\title{
LA IGLESIA DE SAN JUAN BAUTISTA, DE CHICLANA \\ II CENTENARIO (1814-2014)
}

\section{TeOdoro Falcón MáRQueZ \\ UNIVERSIDAD DE SEVILLA}

\begin{abstract}
RESUMEN: Se ha conmemorado el II Centenario de la construcción de esta iglesia, que es el templo neoclásico más importante de la Bahía de Cádiz y su entorno y, tal vez, de Andalucía. En este ensayo se analiza su proceso constructivo y los siete proyectos originales que se conservan, realizados por el arquitecto Torcuato Benjumeda, en los que se representan la planta, alzado, sección longitudinal y diseño de retablos.
\end{abstract}

PALABRAS CLAVE: Neoclásico en Cádiz; Torcuato Cayón; Torcuato Benjumeda; Riedmayer; iglesia mayor de Chiclana.

\section{CHURCH OF SAN JUAN BAUTISTA OF CHICLANA}

ABSTRACT: Has commemorated the Bicentennial of the construction of this churh, which is the most important neoclassical temple of the Bay of Cadiz and its environment and, perhaps, of Andalusia. In this essay is analyzed the construction process and the original seven projets that still preserved, made by the architect Torcuato Benjumeda, where the plan, elevation, section and longitudinal design altarpieces are represented.

KEY WORDS: Neoclassical in Cadiz; Torcuato Cayón; Torcuato Benjumeda; Riedmayer; Great Church of Chiclana.

Recibido: 17-09-14/Aceptado: 07-10-2014

\footnotetext{
${ }^{1}$ El texto forma parte de la conferencia impartida en este templo el 27 de junio de 2014, con motivo del Bicentenario de su construcción.
} 
El pasado día 24 de junio de 2014 se celebró con gran solemnidad la ceremonia conmemorativa del Bicentenario de la construcción de este templo, que se consagró ese mismo día y mes de 1814. Con el tiempo el edificio ha resultado ser no solo la iglesia neoclásica más importante de la Bahía de Cádiz y su entorno, sino de toda Andalucía (imagen 1). La mayor parte de los datos que aquí facilitamos los publicamos hace ya cuarenta años ${ }^{2}$.

Su construcción se llevó a cabo entre 1776 y 1814. En ese marco coyuntural Chiclana, y las poblaciones de la Bahía de Cádiz, experimentaron un doble proceso, de signo contrario. En primer lugar entre las décadas de 1779-90 tuvo lugar en este escenario el período álgido de su economía. Si desde 1717 el puerto de Cádiz tuvo el monopolio del comercio americano, pese a los sucesivos decretos de libertad de comercio que se promulgaron a partir de 1765, la economía gaditana no quedó perjudicada, sino que siguió en aumento. García-Baquero sostiene que entre 1778-88 las exportaciones de esa ciudad experimentaron un incremento del 420\%. La población, asimismo, aumentó un 86,25\%, con relación a la de primeros de ese siglo $\mathrm{XVIII}^{3}$. Este hecho incidió en la arquitectura y urbanismo de la ciudad de Cádiz, que agotó entonces el espacio del istmo, creciendo verticalmente, edificándose casas de 4 o 5 plantas, fenómeno que no tiene parangón con el resto de las ciudades andaluzas. La tendencia alcista del comercio alcanzó su punto culminante en 1792. Con relación a 1778 supuso un incremento del 512\%. En ese año de 1792 se promulgaron las Ordenanzas de Cádiz, que supusieron el punto de partida oficial de la arquitectura neoclásica en la ciudad ${ }^{4}$. El aspecto que ofrecía en esa época boyante, cuando se construyeron además los edificios más representativos, se ofrece en la maqueta

\footnotetext{
${ }^{2}$ FALCÓN MÁRQUEZ, Teodoro. Torcuato Benjumeda y la arquitectura neoclásica en Cádiz: Cádiz, Instituto de Estudios Gaditanos, Diputación, 1974. Idem. "El exámen de alarife de Torcuato Benjumeda". Boletín del Museo de B.A. de Cádiz”, no 1. Cádiz, 1978. Otros datos los hemos publicado en: La Babia de Cádiz en tiempos de Carlos III (Catálogo de la Exposición). Cádiz, Consejería de Obras Públicas y Transportes/Ayuntamiento de Cádiz, 1988. El litoral andaluz en tiempos de Carlos III (Catálogo de la Exposición). Málaga, Consejería de Obras Públicas y Transportes/Diputación de Málaga, 1988. Véase también: ANTÓN SOLÉ, Pablo. "La etapa de juventud del arquitecto Torcuato Benjumeda y su tiempo". Anales de la R.A. de B.A. de Cádiz, no 5. Cádiz, 1987. BANDA Y VARGAS, Antonio de la. "Torcuato Benjumeda en la Academia de Bellas Artes de Cádiz" (en la misma revista, número y año). CIRICI NARVÁEZ, Juan Ramón. Juan de la Vega. La arquitectura gaditana del siglo XIX. Cádiz, Colegio Oficial de Arquitectos de Andalucía Occidental, 1992, pp. 41-42.

3 GARCÍA-BAQUERO GONZÁLEZ, Antonio. Comercio colonial y guerras revolucionarias. Sevilla, 1972. Idem. Comercio y burguesía mercantil en el Cádiz de la Carrera de Indias. Cádiz, Diputación, 1991. Idem. Cádizy el Atlántico (1717-1778). Cádiz, Diputación, 1998. BARRIENTOS GARCÍA, María del Mar. "Cádiz, su puerto y su bahía: la aplicación de las leyes de libre comercio". En Trocadero, no 21-22. Cádiz, 2010. PÉREZ SERRANO, J. La población de Cádiz a fines del Antiguo Régimen (su estructura y mecanismos de renovación (1775-1800). Cádiz, 1989.

${ }^{4}$ FALCÓN (1974). Apéndice documental, pp.112-139.
} 
de Cádiz realizada por el ingeniero Alfonso Ximénez entre 1777-79, que se conserva en el Museo Histórico Municipal ${ }^{5}$.

Si en ese período alcanzó esta zona su cenit, inmediatamente a partir de 1792 se inició su ocaso, a causa de los decretos de libertad de comercio a los neutrales, a la guerra con Inglaterra (batalla de Trafalgar, 1805), el Sitio de Cádiz por los franceses y la emancipación de las colonias americanas ${ }^{6}$. En el caso particular de la villa de Chiclana influyó, además, la fiebre amarilla de comienzos del siglo XIX; la epidemia de viruela, que causó gran mortandad, y la invasión francesa, desde el 7 de febrero de 1810 hasta el 25 de agosto de 1812. Por tanto, la construcción de esta iglesia se inició en el momento de máximo esplendor de la bahía de Cádiz y su zona de influencia, en la década de 1770, quedando paralizada a comienzos del siglo XIX por las causas reseñadas, bendiciéndose en 1814 al cabo de 38 años de su inicio, sin concluir. Entonces Chiclana tenía una población que rondaba los 7.000 habitantes $^{7}$.

El proyecto inicial lo realizó Torcuato Cayón de la Vega (1725-83) el arquitecto más importante de la zona, activo en las décadas de 1750-70. Maestro de maestros tuvo como discípulos a Torcuato Benjumeda y a Miguel de Olivares, y como yerno a Ventura Rodríguez, casado con su hija Micaela. Cayón marca la transición entre la arquitectura barroca y la neoclásica en este marco. Haciendo una apretada síntesis de su obra diremos que fue maestro mayor de la ciudad de Cádiz en 1763. En esa ciudad construyó la Puerta de Tierra en 1756. Fue maestro mayor de su catedral (1759-83), en donde modificó los planos de Vicente Acero para reducir la altura de las torres, proyectó las fachadas alabeadas, así como un tabernáculo para la capilla mayor. En 1763 edificó el Hospicio en la Caleta, proyectó las iglesias de San José y San Pablo (1781) y al año siguiente trazó e inició la Santa Cueva (capilla subterránea). En la década de 1770 fue maestro mayor de la colegiata de Jerez (actual catedral), donde diseñó la cúpula, el coro y los reductos, tareas que fueron ejecutadas por su discípulo, Miguel de Olivares. En 1778 proyectó el edificio del Ayuntamiento de San Fernando, y entre 1772-74, estando en Chiclana, construyó la ermita de Santa Ana, que sería reconstruida a mediados del siglo XIX ${ }^{8}$. Se conserva un retrato póstumo, realizado por un pintor anónimo en 1787, para la desaparecida capilla de San

\footnotetext{
5 JIMÉNEZ MATA, Juan. "La ciudad de Cádiz y su bajorrelieve de 1777-79”. En Periferia, no 4. C.O.A.A.O, 1996. MARTÍNEZ MONTIEL, Luis Francisco. "La maqueta de Cádiz, algunos apuntes sobre la construcción y su autor". Laboratorio de Arte, no 12. Sevilla, 1999.

${ }^{6}$ RAMOS SANTANA, Alberto. Cádiz en el siglo XIX. Editorial Sílex, 1992.

7 CASTILLO GARCÍA, A., VELÁZQUEZ-GAZTELU, F., GONZÁLEZ DE CALDAS, M.C. Los pueblos de la provincia de Cádiz. Chiclana de la Frontera. Cádiz, Diputación, 1982, p.163.

8 ANTÓN SOLÉ, Pablo. "El arquitecto gaditano Torcuato Cayón en el II Centenario de su muerte". Anales de la Real Academia de Bellas Artes de Cádiz: n¹, pp. 55-68. Cádiz, 1983.
} 
Antonio, en San Fernando. En el lienzo figura sentado tras una mesa, diseñando unas trazas 9 .

El principal protagonista de nuestro ensayo, Torcuato José Benjumeda y Laguada (1757-1836), fue el arquitecto neoclásico más importante, no solo de la Bahía de Cádiz y su entorno, sino de Andalucía. Discípulo y ahijado de Cayón, le sustituyó a su muerte en la dirección de diversos edificios. Haciendo también una apretada síntesis de su obra, diremos que entre sus títulos y distinciones ostentó el cargo de Director de Arquitectura de la Academia de Cádiz y Académico de Mérito de la de San Fernando de Madrid (1793). Tomó parte activa en el Sitio de Cádiz, llegando a ser primero subteniente (1809) y capitán de la $2^{\text {a }}$ Compañía del batallón de Artilleros Voluntarios Distinguidos (1821). Entre las obras en las que intervino en la ciudad de Cádiz destacaremos la Cárcel Real (1794), la fachada del Ayuntamiento (1819) y numerosos proyectos urbanísticos. Construyó las iglesias de San José y san Pablo (1783-87), amplió la iglesia del Rosario (1793-96), construyó la capilla sacramental de la Santa Cueva (Oratorio alto, 1793-96); la iglesia de San José, de Puerto Real (1783-94), y estuvo al frente de las obras del Ayuntamiento de San Fernando, desde 1802. De este arquitecto se conserva un retrato realizado por Juan Rodríguez, "el Panadero", fechado en 1813, cuando tenía 56 años. Es el mismo aspecto que tendría al año siguiente, cuando se estrenó la iglesia de Chiclana. El lienzo fue donado a la Academia gaditana en 1861, por su hijo Francisco de Paula. En la actualidad se halla depositado en el Museo de Bellas Artes. En el cuadro figura la siguiente leyenda:

“D. TORCUATO JOSÉ BENJUMEDA, CAPITÁN DEL BATALLÓN DE ARTILLE/ROS DE LÍNEA VOLUNTARIOS DISTINGUIDOS DE CÁDIZ, ARQUITECTO MA/YOR TITULAR PRIMERO DE LA MISMA CIUDAD, DIRECTOR DE ARQUI/TECTURA EN SU ACADEMIA DE BELLAS ARTES, ACADÉMICO DE MÉRI/TO DE LA DE SAN FERNANDO DE MADRID/MURIÓ EN 15 DE ABRIL DE 1836"”.

La intervención de Cayón en la iglesia de San Juan Bautista de Chiclana duró 7 años, de los 38 de su proceso constructivo. Se inició en febrero de 1776. Para la cimentación se utilizaron piedras procedentes de las ruinas del castillo. La piedra ostionera de la Barrosa se empleó para el zócalo, y para los muros piedras procedentes de la cantera

\footnotetext{
${ }^{9}$ Lo reproducen en blanco y negro, en fotografías de escasa calidad: ESCALERA, Manuel de la. Nomenclator de las calles de Cádiry y explicación del significado de cada uno de sus nombres. Cádiz, 1856. CLAVIJO, Salvador. La ciudad de San Fernando. Historia y Espiritu. San Fernando, 1961. SOLÍS LLORENTE, Carlos. "El retrato de Torcuato Cayón”. Anales de la R.A. de B.A. de Cádiz, no 9. Cádiz, 1991, pp. 149-155.

${ }^{10}$ El lienzo mide: 1,24 x 0,87. El arquitecto figura con el uniforme de capitán de Voluntarios de Artillería. Esta Compañía de Voluntarios Distinguidos se formó con alumnos de Arquitectura de la Escuela de Bellas Artes.
} 
del Jardal, de la misma localidad. Asimismo se utilizaron piedras del depósito de la catedral de Cádiz, que entonces se construía por Cayón y ladrillos de Sevilla. El grupo escultórico de la portada se hizo con piedra blanca de Estepa. El seguimiento de las obras se realizó bajo la supervisión de una Junta de Obras, designada por el obispo de Cádiz, fray Tomás del Valle. Estaba integrada por doce miembros, seis clérigos y seis seglares. Estaba al frente de ella el corregidor, como presidente; el vicario: Vicente Torquemada; los presbíteros: José María Blanco, Fernando Lozano y Martín Jiménez; el síndico personero del Ayuntamiento y los diputados: Fernando Muñoz, Jerónimo Cruces, Juan Bautista Fernández y Antonio Lozano; el tesorero: Antonio Pizano, y como secretario: el escribano del Cabildo: Francisco de Paula de Valdevino.

Para la construcción del templo colaboraron de forma especial los fieles, así como determinados personajes, tales como Antonio Pizano y el conde de Maule. Cuando escasearon los fondos se acudió al Consejo de Castilla. Como sucedió en 12 de marzo de 1788, por parte de la Justicia y Regimiento de la villa para que se le concedieran los arbitrios necesarios, también se concedieron en 1810; en enero de 1816 solicitó la Junta la prórroga del último arbitrio sobre vinos y licores ${ }^{11}$. Entre los asiduos colaboradores en la construcción del templo hemos citado a Antonio Pizano, un comerciante con las Indias que fue tesorero de la Junta de Obras. Sobre un pilar de la iglesia se ha colocado un lienzo con un retrato suyo, póstumo (O/L. 1,33 x 0,93). Es de autor anónimo y debe fecharse hacia 1833/4. Al pie pone la siguiente leyenda:

"DON ANTONIO PIZANO NACIÓ EN ESTA VILLA EL DÍA 15 DE ENERO DE 1756, VARÓN VIRTUO/SO A CUYA PIEDAD, DESPRENDIMIENTOS Y SOLICITUD SE DEBIÓ EN GRAN PARTE SE/ACTIVASE LA OBRA DE ESTE HERMOSO TEMPLO HABILITÁNDOSE PARA EL CULTO/DIVINO Y SE CELEBRASE LA PRIMERA MISA, QUE SE EFECTUÓ EL DÍA 24 DE JU/NIO DE 1814/ FALLECIÓ EN ESTA VILLA EL DÍA 20 DE ABRIL DE 1833”.

El otro gran protagonista fue Nicolás de la Cruz Bahamonde (Talca h. 1757-Cádiz 1828), un chileno que fue militar, bibliófilo, coleccionista y comerciante ilustrado. Fue distinguido como Caballero de la Real Orden de Carlos III (1797), nombrándole Carlos IV conde de Maule en 9 de abril de 1810. Entre sus publicaciones destaca el Viage de España,

\footnotetext{
11 Archivo parroquial de San Juan Bautista de Chiclana (A.P.S.J.B. Ch.). Legajo de obras, nº1. Juntas de 14 de octubre de 1787, de 17 de noviembre de 1791, de 20 de febrero de 1798. Informe de Don Nicolás Martínez, vicario eclesiástico y cura rector de la iglesia... y Don Antonio Pizano...vocales, fechado en 3 de enero de 1832.
} 
Francia e Italia (Madrid-Cádiz, 1806-1813, XIV volúmenes) ${ }^{12}$. Fue además uno de los grandes impulsores de la Escuela de Nobles Artes de Cádiz y contribuyó a la construcción de algunas iglesias de esa ciudad. Colaboró generosamente en la construcción de esta parroquia, de forma particular en el cerramiento de la cúpula. Al pie del retrato de Antonio Pizano hay una lápida con el siguiente texto:

"EL DÍA 10 DE FEBRERO DE 1776 SE ABRIERON LOS /CIMIENTOS DE ESTA STA. IGLESIA PARROQUIAL DEL/ SR. S. JUAN BAUTISTA, COLOCANDO LA PRIMERA PIEDRA/D. ANDRÉS DEL BARCO CANÓNIGO LECTORAL/DE CÁDIZ, COMISIONADO POR EL YLMO. SR. D. FR./ TOMÁS DEL VALLE, OBISPO DE LA DIÓCESIS, BAJO LA/DIRECCIÓN DEL ARQUITECTO D. TORCUATO CAYÓN/SE COSTEÓ LA OBRA CON EL PRODUCTO DEL BENEFICIO/ PARROQUIAL Y ARBITRIOS CONCEDIDOS POR EL REY. EN/FEBRERO DE 1810 SE PARALIZÓ POR LA INVASIÓN DE LAS /TROPAS ENEMIGAS. EN ENERO DE 1813 VOLVIÓ A CONTINUARSE CON LAS OFRENDAS DE LOS FIELES DE ESTA/VILLA Y DE LA CIUDAD DE CÁDIZ, Y AL ZELO Y ESFUERZOS/DE LOS SRES. CONDE DE MAULE Y D. ANTONIO PIZANO/SE DEBIÓ QUE EN LA TARDE DEL 23 DE JUNIO DE 1814 SE/BENDIJESE Y TRASLADASE LA DIVINA MAJESTAD POR/EL SR. VICARIO CAPITULAR DE LA DIÓCESIS, DON MARIANO/ESPERANZA. Y EN LA MAÑANA SIGUIENTE CELEBRASE/LA PRIMERA MISA, PREDICANDO EL VIRTUOSO Y EMINEN/TE ORADOR DR. D. ANTONIO CABRERA, NATURAL DE ESTA VILLA Y CANÓNIGO MAGISTRAL DE LA CATEDRAL DE CÁDIZ".

Recientemente, en noviembre de 2011, se expuso en Sevilla en pública subasta, en la sede de la Fundación Cajasol, un lienzo que tiene especial interés en el panorama artístico, ya que se trata de la vista más antigua de Chiclana. Se trata de un óleo sobre lienzo que mide 0,95 x 1,40, firmado por Franz Xavier Riedmayer, en Cádiz en 1806. Representa una vista de la villa desde la ermita de Santa Ana, en donde figuran Nicolás Cruz Bahamonde (luego conde de Maule), con cerca de 50 años, y el joven pintor alemán autor del lienzo ${ }^{13}$. A este óleo volveremos cuando hablemos de los alzados de la iglesia.

\footnotetext{
12 RAVINA MARTÍN, Manuel. "Conde de Maule. De Cádiz y su comercio”. En la edición y estudio preliminar del tomo XIII del Viage de España...Cádiz, Universidad, 1997.

${ }^{13} \mathrm{El}$ cuadro no fue subastado. Con posterioridad se expuso en Chiclana por el Ayuntamiento, en espera de una mejor coyuntura económica para que sea adquirido por esta institución.
} 


\section{Análisis arquitectónico y proceso constructivo}

En nuestra monografía sobre Benjumeda no analizamos cuáles fueron las fuentes de información del arquitecto. Ahora es el momento de hacer una introducción al tema, para observar de dónde vienen algunos de los esquemas compositivos y decorativos que figuran en este templo. Sabido es que se formó con su tío y padrino Torcuato Cayón, en cuya escuela familiar estudió desde los diez años. Evidentemente tuvo que consultar su biblioteca, cuya relación de obras conocemos a través del inventario post mortem, fechado el 31 de diciembre de 1789, en la Isla de León ${ }^{14}$. Además de obras de religión, de literatura y filosofía y de la Iconología, de Ripa, destacan tratados de los grandes arquitectos, desde la Antigüedad al Barroco. En la relación se cita el "Libro de Alberto". Es el Tratado de arquitectura y urbanismo militar, publicado por Alberto Durero en 1527. También se indican los tratados de Palladio (Los cuatro libros de Arquitectura) y Viñola( Regla de los cinco órdenes) ${ }^{15}$, además de una edición de Vitrubio (Los diez libros de Arquitectura). Por otra parte consta un “cuaderno con diseños de El Escorial”. Debe ser la obra de Pierre Perret, Scenographía totius fabricae S. Laurenti in Escoriali (1589); se cita el Templum vaticanum, de Carlo Fontana (1694). Se alude a la "Fortificación de Guarino", que tiene que ser la Architettura civile de Guarino Guarini (obra póstuma publicada en 1737). Asimismo consta "la iglesia de Turín", que debe aludir a la capilla del Santo Sudario, del mismo arquitecto (Capella delle Sacra Sindone). Por otra parte, la viuda de Cayón, María de Santamán, como albacea y heredera, además de madrina de Benjumeda, le entregó de su padrino un reloj de plata, un espadín y "la obra de Matemáticas del Padre Tosca". Se trata de Tomás Vicente Tosca y Mascó, autor del Compendio mathemático, en que se contiene todas las materias más principales de las ciencias que se tratan de la cantidad (Madrid, 1727, 9 tomos). Aunque no se cite en este inventario, como veremos, en Benjumeda influyeron notablemente, además, los tratados de Arquitectura de Sebastián Serlio y el monasterio de San Lorenzo de El Escorial. Del Barroco español se advierte la influencia del tratado de Fray Lorenzo de San Nicolás, Arte y uso de la Arquitectura (primera edición de 1639), en particular en el modelo de cúpula, de tambor cilíndrico por el interior y prismático al exterior, y del Neoclasico, de Ventura Rodríguez por el tipo de columnas jónicas con guirnaldas entre las volutas (iglesia de la Encarnación, de Madrid), y de Sabatini, también en el mismo prototipo de columnas jónicas con guirnaldas (Puerta de

\footnotetext{
14 Se inserta en el libro de MARTÍNEZ MONTIEL, Luis F. San Fernando, una ciudad de las luces. Arquitectura y urbanismo (1766-1868). Cádiz, 1995, pp.298-303.

15 La Academia de Nobles Artes de Cádiz, fundada en 1789, tuvo desde su creación a Benjumeda como Teniente de Arquitectura, llegando a ser Presidente en 1817. En la Academia de Bellas Artes, que tenía anexa, se entregaban ejemplares del tratado de Viñola, editados en Cádiz, en los premios final de curso.
} 
Alcalá), así como en los proyectos de planta elíptica y de retablos, como analizaremos a continuación.

En julio de 1969, en el curso de los trabajos de investigación que realizaba en este templo para mi tesis doctoral sobre Torcuato Benjumeda, tuve la oportunidad de encontrar cuatro planos inéditos firmados por este arquitecto, que se hallaban en la cripta de la iglesia mayor de Chiclana, entonces convertida en un trastero. Representan a varios altares para la capilla mayor, capillas laterales y los de los dos primeros tramos del cuerpo de la iglesia. Datan de 1816. Por otra parte el arquitecto y académico gaditano, don Carlos Solís Llorente, puso a nuestra disposición otros tres proyectos originales del mismo arquitecto, existentes en su colección Se trataba de la planta, sección longitudinal y alzado de la tribuna de los pies. Su cronología abarca desde 1786 a 1806 ${ }^{16}$. La planta está fechada en 1806 (imagen 2). Muestra el edificio de forma rectangular, de tres naves, con pilares cruciformes, con acusado esviaje en el muro de la nave de la Epístola (c/Martín Jiménez). Es de testero plano. En él se halla la capilla mayor y el coro y a los lados dos capillas de planta elíptica, con bóveda de ese tipo y linterna: la de San Pedro (Cristo de Medinaceli) en el lado de la Epístola, y la Sacramental en la del Evangelio. Si buscamos antecedentes de ese modelo existe un largo recorrido desde el Renacimiento y el Barroco hasta llegar al Neoclásico: destacaremos, entre otros "la planta de templo ovalado" del Libro V de Sebastián Serlio (París, 1547); las iglesias de San Andrea en via Flaminia y Santa Ana dei Palafreneri, de Viñola, en la década de 1550; la Sala Capitular de la catedral de Sevilla, proyectada por Hernán Ruiz II en 1568; la iglesia de San Giacomo in Augusta de Roma, terminada en 1602 bajo la dirección de Carlo Maderno, según proyecto de Francesco da Volterra; el Oratorio de San Felipe Neri de Cádiz, construido por Blas Díaz entre 1688-1719; el Sagrario de la catedral de Jaén, proyectado por Ventura Rodríguez en 1761; la planta de la iglesia de Santa Ana de Valladolid, proyectada por Sabatini en 1778. El propio Benjumeda proyectó de forma elíptica el Salón de Sesiones del Ayuntamiento de Cádiz en $1816^{17}$. En la planta de la iglesia de San Juan de Chiclana observamos que tiene transacristía. En este proyecto figura trazado en sentido transversal al eje de la iglesia, construyéndose con posterioridad en el mismo eje. A la izquierda hay una pequeña dependencia para el aguamanil y a la derecha la sala capitular, que nunca se construyó, y la escalera de acceso a la cripta. También figuran en la planta los retablos y las escaleras de caracol, a los pies, para acceder a la tribuna y a la

\footnotetext{
${ }^{16}$ En la actualidad se hallan en Sevilla, en la colección de los herederos.

${ }^{17}$ FALCÓN (1984), lam. XV. Véase RODRÍGUEZ G. DE CEBALLOS, Alfonso. "La planta elíptica: de El Escorial al Clasicismo". Anuario del Departamento de Historia y Teoría del Arte. Madrid, Universidad Autónoma, II, 1990, pp.151-172.
} 
terraza superior. En la actualidad la del lado Norte está parcialmente cegada, prosiguiendo desde la tribuna.

En la leyenda figuran los siguientes textos: "Planta de la Yglesia Parroquial de la villa de Chiclana de la Frontera. Sala capitular, aguamanil, coro. Alzado y perfil de la Sacristía. Corte por C.D. Planta de la iglesia parroquial de la villa de Chiclana de la Frontera en la qual se demuestra de color roxo las obras que se han de concluir de la Iglesia, como son: altares, coro, sacristía, sala capitular y las torres, con la forma con que se les debe dar adaptando a lo que permite la fábrica que ya está executada. Atrios. Gradería. Aprobado por la Academia en Junta ordinaria de 2 de febrero de 1806. Isidro Bosarte, secretario. Madrid, enero de 1806. Silvestre Pérez, Don Bartolomé Muñoz”. Aunque no se especifique faltaba además la construcción de la cúpula.

Otro de los planos, como todos ellos a tinta y aguada, es la sección longitudinal, fechada en 1786 (imagen 3). En la leyenda pone: "Vista interior cortada por la línea A.B. a lo largo del Plano de la Iglesia Parroquial de la villa de Chiclana de la Frontera"/Cádiz, julio 1786/Por el arquitecto Torcuato Joseph Benjumeda”. En esa fecha estaba el templo aún en alberca, sin terminar de abovedar; tampoco estaba construido el cuerpo de luces, la fachada principal y las dependencias de la cabecera. A la izquierda del dibujo se aprecia la cripta, que era el lugar de entierros para los miembros de la Venerable Hermandad de San Pedro, integrada por clérigos. Este hecho se constata por los textos de las lápidas que subsisten ${ }^{18}$. En ellas figuran tras sus nombres, epígrafes como los siguientes: "presbítero y capellán de la Armada", "presbítero doctoral", "presbítero y cura castrense", "cura y vicario que fue de esta villa". Asimismo se aprecia en el plano otra cripta a los pies del templo, que se halla cegada, como también lo está la ventana de ventilación hacia la c/Martín Jiménez.

Llegados a este punto conviene retomar el discurso expositivo y aludir a los alzados del templo, que guardan estrecho paralelismo con otras iglesias del tándem CayónBenjumeda, de forma especial con la de San José de Cádiz. Los pilares son en ambos casos de orden jónico, decorados con pilastras jónicas, con guirnaldas entre las volutas y ovas. Los de este templo son seis, de sección cruciforme. Obviamente están reforzados los torales, que sostienen la cúpula y los de la capilla mayor. Todos ellos se peraltan con trozos de entablamento, modelo que tiene sus antecedentes en las catedrales de Granada, Málaga y Cádiz, entre otras (imagen 4). Las naves son prácticamente de la misma altura y las bóvedas son vaídas. Las de aquí alternan los tramos con decoración de círculos y rectángulos

\footnotetext{
18 Aunque allí figuran, la cripta se ha habilitado para actividades culturales.
} 
concéntricos. Las ventanas son termales, es decir, semicirculares divididas en tres luces, aunque aquí están cegadas las extremas.

La cúpula que estaba prevista con linterna, quedó sin ese remate. Benjumeda la describe como "media naranja". Cuando terminó la invasión francesa en 1812 aún no estaba construida, como puede apreciarse en el lienzo de Riedmayer, de 1806. Por esa razón se construyó una provisional de madera en agosto de 1812. Meses después de la consagración del templo, en noviembre de 1814, hubo que cerrar al culto la iglesia porque se llovía ese casquete. La cúpula definitiva se edificó entre 1815-17, sin revestimiento ni decoración ${ }^{19}$. Las pechinas muestran molduras ovaladas, previstas tal vez para albergar relieves de los Evangelistas, que nunca se realizaron. En 1825 Benjumeda presentó cuatro proyectos para ultimarla. Se trataba de revestirla exteriormente con ladrillos de Sevilla, azulejos vidriados de Valencia; chapas de cinc, procedentes de Rusia, o con planchas de plomo. Se decidió revestirla con ladrillos procedentes de Sevilla ${ }^{20}$. Más recientemente, entre 1984-86, se cubrió con azulejos azules y blancos, bajo la dirección de los arquitectos González de la Peña y González Fusteguera. Siguiendo un modelo propuesto por fray Lorenzo de San Nicolás, muestra -como la iglesia de referencia de Cádiz- un tambor cilíndrico por el interior y poligonal al exterior ${ }^{21}$. Al no haberse concluido el edificio en su momento, faltan las pilastras jónicas que la iban a decorar, así como los remates con las esferas de piedra.

Otro de los dibujos conservados es el que representa el alzado de la tribuna de los pies (imagen 5). En la leyenda pone: "Vista interior cortada por la línea C.D. a lo ancho del Plano de la Yglesia Parro/quial de la villa de Chiclana de la Frontera, que se está construyendo. Cádiz-1786. Por el arquitecto Torquato Joseph Benjumeda”. Su ejecución debió llevarse a cabo a finales de la década de 1790, conjuntamente con el exterior de la fachada. El dibujo es muy elegante, buscando la simetría, con decoración a base de figuras geométricas: semicírculos, triángulos y rectángulos. Muestra sendos antepechos de balaustres, en correspondencia con las tres naves. La fachada se construyó entre 1791-98. En enero de ese último año el arquitecto presentó una relación de materiales que había que

\footnotetext{
19 A.P.S.J.B.Ch. Legajo de obras no 1. Informe de Benjumeda (Resto de 1815-1816 y 1817): "Volvió a seguirse la obra desde Agosto de 1815 hasta Agosto de 1817, para la formación del cuerpo de luces, media naranja, sacristía y oficinas; son 25 meses que al respecto dicho importa 11.250 rs.vn. y bajando 2.000 que mandó el Sr. Conde de Maule, por vía de gratificación, cuando se cerró la cúpula se restan: 9.250". Idem. Legajo de obras $n^{\circ}$ 3: "Contrata para cerrar la cúpula". Informe presentado por Don Antonio Pizano a la Junta de Obras. Chiclana, 30 de diciembre de 1818.

${ }^{20}$ A.P.S.J.B. Ch. Informe de Benjumeda fechado en 23 de noviembre de 1825.

21 Arte y uso de la arquitectura. $2^{a}$ parte. Madrid, 1665. Véase FALCÓN, Teodoro. En Libros del Fondo Antiguo del Laboratorio de Arte. Exposición conmemorativa del I Centenario del Laboratorio de Arte (1907-2007). Sevilla, 2007, pp. 44-47.
} 
recopilar para concluirla, así como el cerramiento de bóvedas, solería de las cubiertas y para concluir las dependencias de la cabecera. El texto es el siguiente:

"Piedra blanda del Jardal. Para la cornisa y frontis exterior: 160 piezas, de distintas medidas. Para las bóvedas: 1000 cantos regulares de diversas medidas.

Piedra dura del Jardal. Para las pechinas, crucero y torres: 60 piezas de distintos tamaños y 400 cantos regulares.

Cantos ordinarios de la Isla o de la Barrosa. 400 jaspes negros para los zócalos de la iglesia.

Piedra quebrada. 200 varas cúbicas de la más sólida y propia para mampostear, de los términos del pueblo, entre ellos los despojos de Santa Ana ${ }^{22}$.

Cal. 200 cahices de la mejor calidad.

Ladrillo de Sevilla o Coria. Para solerías y cubiertas: 10 ó 20 millares bien cocidos.

Maderas. Para los cuartos y oficinas al lado del presbiterio, que deben cubrirse para estribo de la bóveda del presbiterio: 70 vigas aunque sean del pueblo, de 6 a 7 varas de largo, 50 tablas de 4 varas" ${ }^{\prime 23}$.

La fachada resultó muy bella y armónica, con amplias perspectivas desde la plaza. Se eleva sobre un zócalo de piedra ostionera. El resto está construido a base de sillares de las canteras locales del Jardal, perfectamente cortados y pulidos. Como la fachada interior muestra asimismo una compartimentación tripartita, con separación a base de pilastras y traspilastras de orden jónico con guirnaldas y decoración de ovas y rosetas. En las calles extremas hay tres tipos de vanos diferentes: rectángulo vertical, óculo y rectángulo apaisado, decorado con dos pares de gotas. Dan luces a sendas escaleras de caracol que permiten acceder a la tribuna y a las cubiertas. Éstas son de terraza, apreciándose en ellas las bóvedas trasdosadas, en ambos casos revestidas de ladrillo.

El cuerpo bajo de la portada ofrece la alternancia de arco y dintel, flanqueado por dos pares de columnas de orden compuesto sobre plinto, que alternativamente avanzan o retroceden. El segundo cuerpo presenta un balcón con balaustres, otros dos pares de columnas del mismo orden, enrasadas y un frontón semicircular, con círculo central, tema que se repite en las calles laterales. El modelo procede de una lámina del tratadista

\footnotetext{
22 Obsérvese que en 1797 la ermita se hallaba arruinada.

23 A.P.S.J.B. Ch. Libro de Juntas de Obras que se inicia en 1797. Informe de Torcuato José Benjumeda de 25 de enero de ese año, inserto en la Junta del día siguiente. "Nota: Para la conclusión de la fachada principal, está acordado poner en el frontón un adorno de piedra de Estepa, que se está trabajando por un escultor de Cádiz, y debe tratarse la conclusión de esta parte de obra si ha de seguir en términos que puede colocarse en sus respectivos sitios antes que la obra de dicho frontón y demás de la fachada imposibilita por muy adelantada la colocación del citado adorno, si no es a costa de crecidos gastos en nuevas andamiadas y otros preparativos indispensables a unos trozos de bastante gravedad, cuales son de los que se componen el citado adorno".
} 
Sebastián Serlio, así como del monasterio de San Lorenzo de El Escorial ${ }^{24}$. Otro tema decorativo que emplea Benjumeda, procedente también de Serlio y del Escorial, es el prototipo de frontón triangular, con el disco central $^{25}$. En la fachada que figura junto al retrato de Antonio Pizano, figura en lugar del balcón una hornacina, que iba a albergar la imagen del santo titular. El entablamento tiene decoración de dentículos y ovas. El tema procede también de Serlio ${ }^{26}$. Este tipo de decoración, como el modelo de las pilastras jónicas, las repite Benjumeda en la fachada del Ayuntamiento de Cádiz (1819). El frontón triangular que corona el conjunto, asimismo está decorado con ovas. En su interior se halla un grupo escultórico en piedra blanca de Estepa, realizado por Cosme Velázquez, el escultor y académico asiduo colaborador en los edificios en los que interviene este arquitecto. Por el documento antes citado se labraba en 1797. Se trata de dos ángeles tenantes que portan un blasón. Aunque se ha manifestado que representa el escudo de las ciudades de Cádiz y de Chiclana, lo cierto es que en él se aprecian castillos y leones, rematándolo la corona real, a la que le falta la parte superior. Es el blasón de Fernando $\mathrm{VII}^{27}$. Los dos campanarios, así como las jarras pétreas que iban a coronar la fachada, no se construyeron. Por esta razón hizo esta función la Torre del Reloj. Se trata de una torre-calle municipal, ubicada sobre una de las puertas de la ciudad. Se reconstruyó en 1764, tras el terremoto de 1755. El arquitecto José María Esteban González hizo en noviembre de 2012 un proyecto de restauración y terminación de la fachada, con los campanarios. El proyecto espera la aprobación y financiación de las instituciones implicadas.

El resto de los dibujos, que encontramos en su día, son los proyectos de altares ${ }^{28}$. El punto de partida de éstos y otros que Benjumeda diseñó para iglesias de Cádiz, se halla en unas reales órdenes de Carlos III de 1777 y 1789, y de Carlos IV de 1791, dictadas a iniciativa del Secretario de la Real Academia de San Fernando, Antonio Ponz, académico y antibarroco, quien con la excusa de evitar incendios propuso que los retablos se realizaran en piedra, mármol, jaspe o de estuco, imitando los otros materiales. Con ello se acabó definitivamente con los modelos tradicionales. Los principales artífices de los nuevos proyectos en España fueron Vicente Rodríguez, Francisco Sabatini y Pedro Arnal. Los

\footnotetext{
${ }^{24}$ Libro IV. Edición de Francisco de Villalpando, Toledo, 1552, lam. XXVI y XLVII. En el Escorial figura en el Patio de los Mascarones. El modelo también lo empleó Benjumeda en el cuerpo central de la fachada de la Cárcel de Cádiz, proyectada en 1794 y en el alzado del Patio del Ayuntamiento de Cádiz, en 1816.

${ }^{25}$ Libro III, lam. XVIII, en la fachada principal del Escorial y en la fachada de la iglesia de San José de Cádiz.

${ }^{26}$ Ibidem, lam. LVII y LIX.

27 En el momento de redactar este artículo el grupo escultórico amenaza gravemente su desaparición, faltándole una pierna a cada ángel y el blasón está sostenido por una malla, de forma "provisional". Esperemos que no desaparezca, como le ha sucedido a los remates de la Cárcel Real y de la fachada de la iglesia de San José de Cádiz, todos ellos realizados por Cosme Velázquez.

${ }^{28}$ En la actualidad se hallan también en la Colección Solís. Se están haciendo gestiones para que se depositen en la iglesia.
} 
proyectos del tabernáculo y altares, que hizo Benjumeda para este templo se realizaron en enero de $1816^{29}$. Si los comparamos con los realizados por sus contemporáneos, veremos especial paralelismo con los trazados por Sabatini ${ }^{30}$. El proyecto del tabernáculo para la capilla mayor tiene la siguiente leyenda (imagen 6): "Pensamiento de Planta y Alzado para el Tabernáculo del Altar Mayor y Sagrario de la iglesia parroquial de la villa de Chiclana, para construirlo de jaspes y bronces, o de madera y estuco, a su imitación. Inventado por el arquitecto Académico de Mérito de la Real de San Fernando, don Torcuato José Benjumeda, que ha dirigido la construcción de la referida Iglesia parroquial". El tabernáculo se organiza con seis columnas de orden compuesto formando un círculo, con su basamento. El baldaquino alberga el sagrario con el manifestador. La decoración escultórica es a base de las tres virtudes teologales. Figurando la $\mathrm{Fe}$ en lo alto y flanqueándolo la Esperanza y la Caridad. Cuando se consagró el templo en 1814 se puso un altar provisional. Debido a que en 1797 se había prohibido la importación de mármoles, a diferencia de otros más ricos proyectados por el mismo arquitecto, como es el caso del que preside la capilla Sacramental de la Santa Cueva, éste se hizo mucho más modesto. En la actualidad alberga la imagen titular de San Juan Bautista, atribuida a Francesco María Galleano (h. 1730). De las tres virtudes solo existe la de la Fe.

Se conserva también el proyecto previsto para los retablos las capillas elípticas, ubicadas en la cabecera de las naves laterales (imagen 7). Su leyenda es la siguiente: "Pensamiento para los Altares de las Capillas del Sagrario y de San Pedro de la Yglesia Parroquial de Chiclana. Por el arquitecto Torquato Joseph Benjumeda". Se trata de un proyecto idéntico para las dos capillas, que consta de un cuerpo, flanqueado por columnas y pilastras jónicas, templete para el sagrario, frontal con decoración de círculos concéntricos, frontón semicircular con ángeles recostados, siguiendo el modelo del frontispicio del Tratado de los Cinco órdenes de Andrea Palladio (Venecia 1570). Remata el conjunto un sol con la paloma del Espíritu Santo. Al parecer estos retablos no se ejecutaron. En la capilla Sacramental se conserva una tabla procedente del templo primitivo. Representa el "Descendimiento de Cristo" (1,74 x 1,36). Está documentado que lo realizó Roque de Balduque hacia 1552, con policromía de Andrés Ramírez. La composición se inspira en un modelo creado por el pintor flamenco Pedro de Campaña.

\footnotetext{
29 A.P.S.J.B.Ch. Legajo de obras no 1: "Por varios planos y dibujos que se me encargaron para el tabernáculo y altares, que firmados por el secretario de la Junta (de obras) existe en mi poder algunos: 3.000 rs.vn." 30 Véase: FERNÁNDEZ MARTÍN, Juan José. Francisco de Sabatini y las obras del convento de San Joaquín y de Santa Ana de Valladolid. Valladolid, Universidad, 1994. La planta elíptica de este templo, la decoración con lienzos de Francisco de Goya y de Ramón Bayeu, así como su retablo mayor (1781-87), muestran evidentes paralelismos con la capilla Sacramental de la Santa Cueva.
} 
Otro de los proyectos es el de los retablos ubicados en el teórico crucero. Su leyenda dice: "Proyecto para los dos altares primeros colaterales de la Iglesia Parroquial de Chiclana. Por el arquitecto de Cádiz D. Torquato Joseph Benjumeda" (imagen 8). Consta de un cuerpo, con cuatro columnas, de las que avanzan dos. Alberga un pequeño templete de base circular para el sagrario. Está flanqueado por las figuras de dos ángeles, habiendo otros dos sedentes en los extremos del ático. El repertorio está inspirado asimismo en el frontispicio del libro de Palladio. Los retablos que hay en su lugar no corresponden a este proyecto. Muestran la alternancia de columnas jónicas y pilastras toscanas. Se rematan con tallas de ángeles niños sedentes y un tondo con ráfagas, en cuyo interior hay sendos lienzos con pinturas alusivas a María. Finalmente diremos que el último proyecto conservado es el de los retablos del segundo tramo, comenzando por la cabecera: "Proyecto para los dos altares segundos colaterales". Es también de un cuerpo, flanqueado por columnas de orden compuesto, dos de ellas avanzadas, con frontón triangular. La decoración escultórica muestra las imágenes de la Fe y la Caridad en los intercolumnios, y en el frontón, dos ángeles portan un blasón. En 1805 se solicitaba al arquitecto que procurara simplificar los proyectos, para reducir gastos, autorizándole a sustituir la piedra por madera estucada ${ }^{31}$. Este dato permite evidenciar que las trazas conservadas son los de 1816, que tampoco se ejecutaron. La no realización de los proyectos originales de Benjumeda, que fueron sustituidos por otros retablos más económicos, es obviamente el resultado de la crisis económica de la época. Este hecho se repite en otros retablos trazados por el mismo arquitecto en diversos templos gaditanos ${ }^{32}$.

\footnotetext{
31 A.P.S.J.B.Ch. Junta de 11 de marzo de 1805.

32 FALCÓN (1974): "Retablo mayor de la parroquia del Rosario", pp.108-112. Para las tipologías de estos modelos de retablos, véase: ALONSO DE LA SIERRA FERNÁNDEZ, Lorenzo. El retablo neoclásico en Cádir. Cádiz, 1989.
} 


\section{ANEXO 1. CUADRO CRONOLÓGICO DE LA CONSTRUCCIÓN DEL TEMPLO}

1776, febrero. Se inician los cimientos, según proyecto de Torcuato Cayón. Comienzan las obras con piedras procedentes de las ruinas del Castillo (cimientos), piedra ostionera de la Barrosa (zócalo) y del Jardal (muros).

1783, enero 11. Fallece Cayón, siendo sustituido por Torcuato Benjumeda.

1786, julio. Benjumeda proyecta la sección longitudinal y el alzado de la tribuna de los pies. Se inicia el abovedamiento del templo. Aparejador: Juan José Benjumeda, su hermano.

1791-98. Se construye la fachada. Decoración escultórica con piedras de Estepa por Cosme Velázquez. Dos ángeles tenantes portan el escudo real de Fernando VII.

1806. Benjumeda proyecta una planta en la que notifica que falta construir la sacristía, coro, sala capitular, torres y la cúpula.

1810-12. Invasión francesa: desde el 7 de febrero de 1810 hasta el 25 de agosto de 1812. El edificio se convierte en cuartel y parque de Artillería. Desaparecen mármoles de la capilla mayor y pilares.

1812, fines de agosto. Se construye una cúpula de madera.

1814, junio 24. Se bendice el templo, sin concluir, al cabo de 38 años.

Invierno: Se cierra la iglesia por filtraciones de la cúpula. Quedaba por hacer el presbiterio y dependencias, el coro, torres, tribuna de los pies y cúpula.

1815-19. Se construye lo que faltaba, a excepción de los campanarios y sala capitular.

La cúpula se cerró en 1819.

1817. Benjumeda proyecta el templete de la capilla mayor y los retablos.

1825. Se reviste la cúpula con ladrillos procedentes de Sevilla. Otras opciones que se barajaron fueron de revestirla con azulejos vidriados de Valencia, con chapas de cinc, procedentes de Rusia o con planchas de plomo.

1984-86. Se reviste la cúpula con azulejos blancos y azules. Dirigen las obras los arquitectos: González de la Peña y González Fustiguera.

2010. El arquitecto José María Esteban González realiza un proyecto de restauración y construcción de los campanarios, pendiente de aprobar. 


\section{ANEXO 2. IMÁGENES}

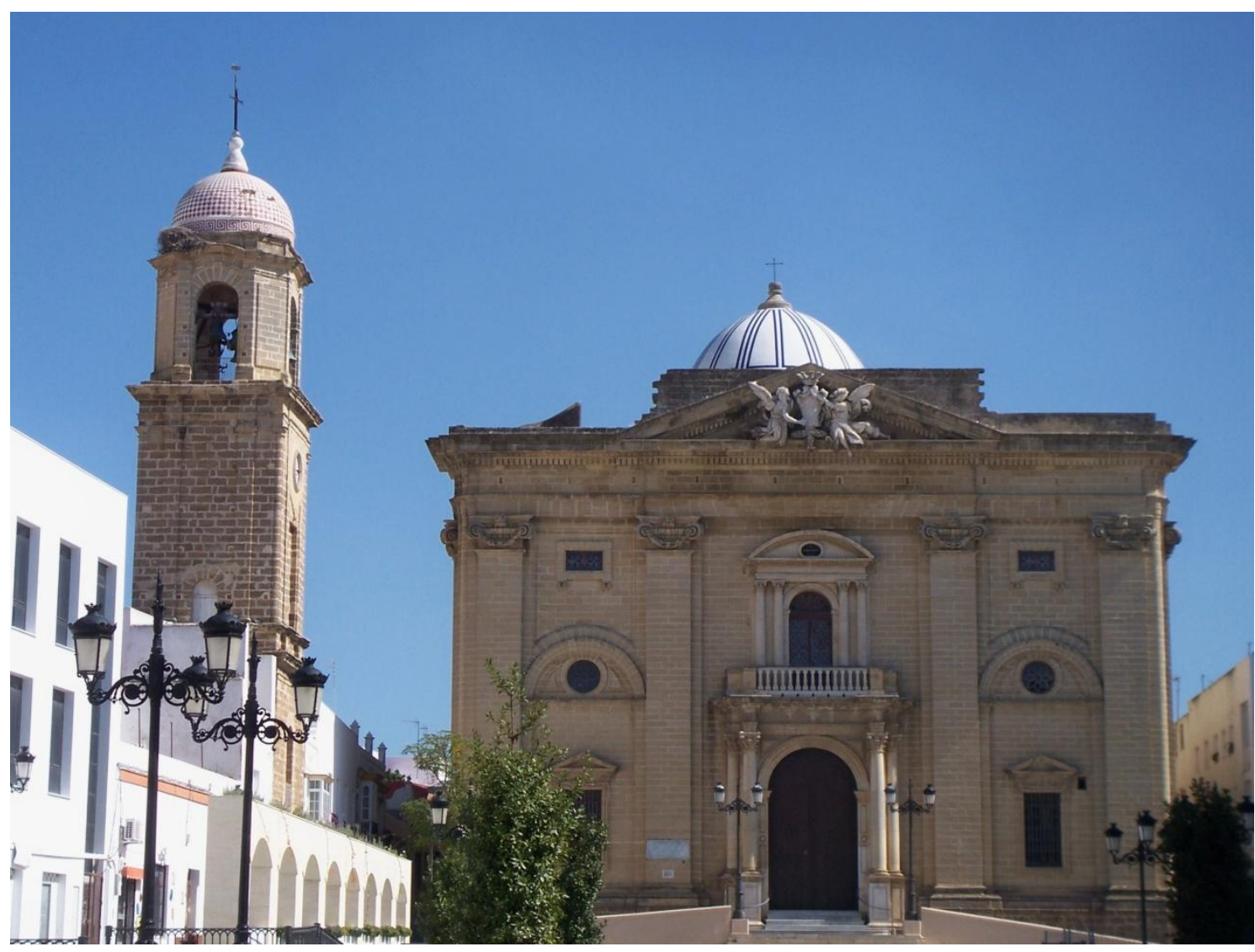

Imagen 1. Fachada principal y Torre del Reloj 


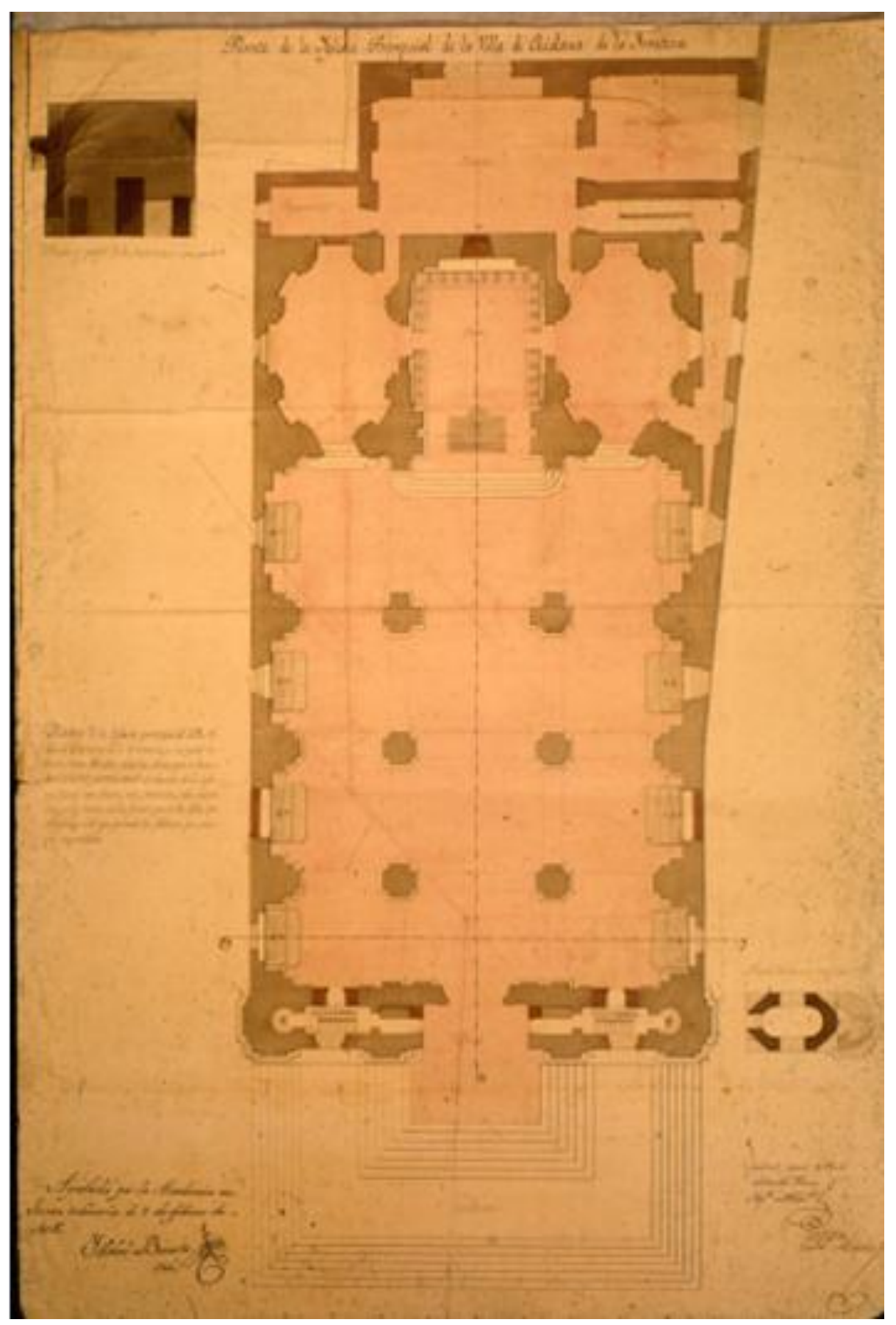

Imagen 2. Proyecto de planta, de 1806 


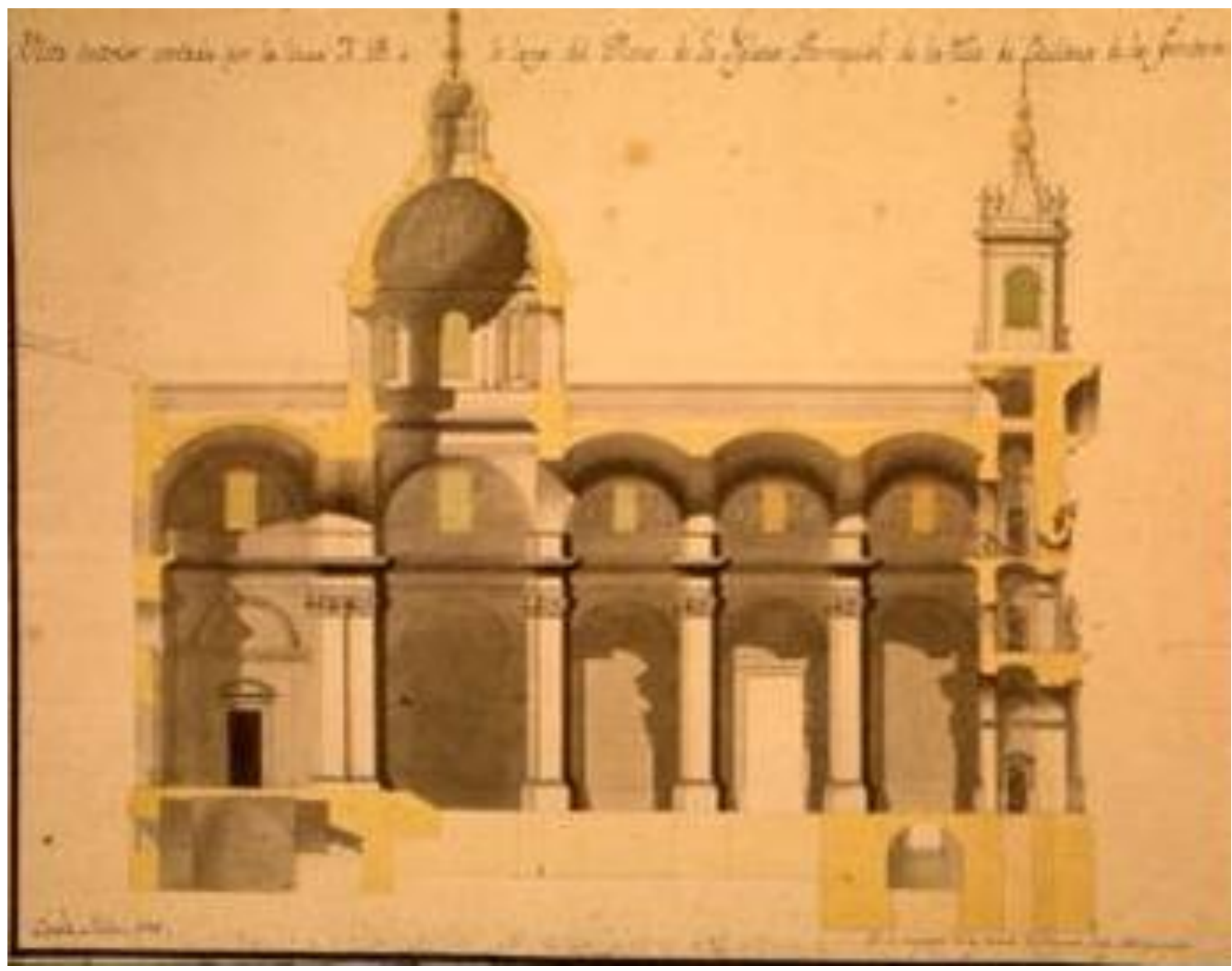

Imagen 3. Sección longitudinal, de 1786 


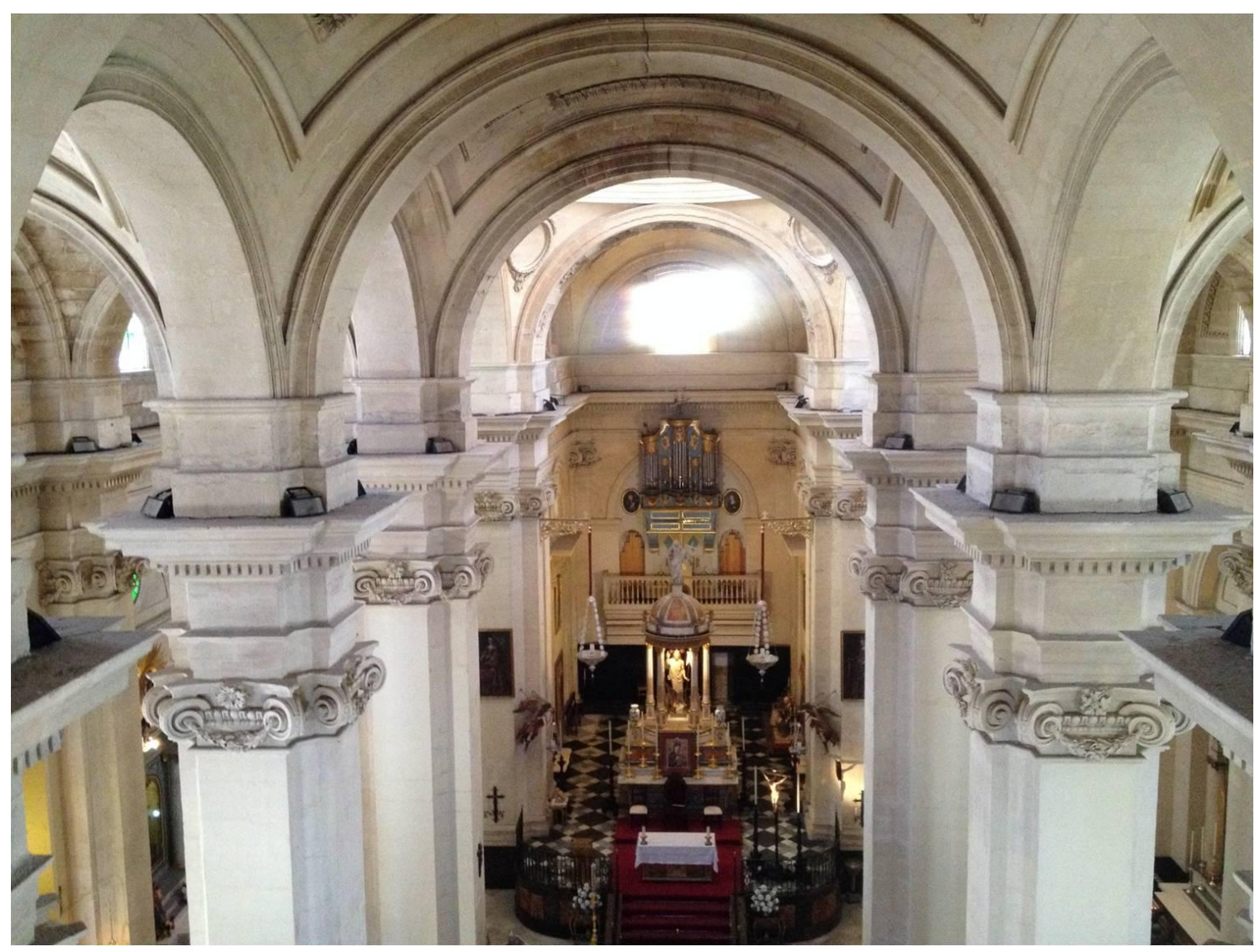

Imagen 4. Nave central con pilares y bóvedas 


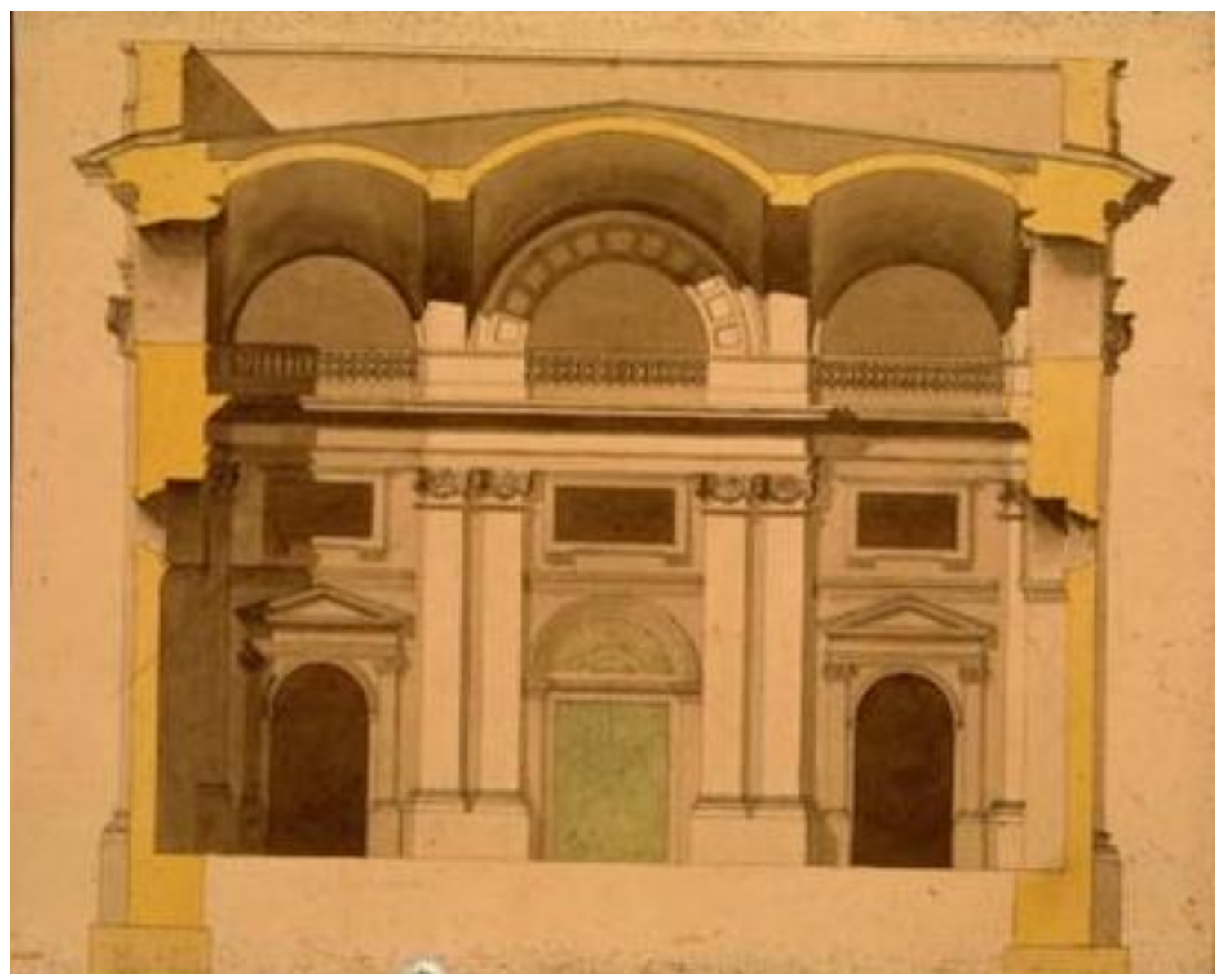

Imagen 5. Alzado de la tribuna de los pies, de 1786 


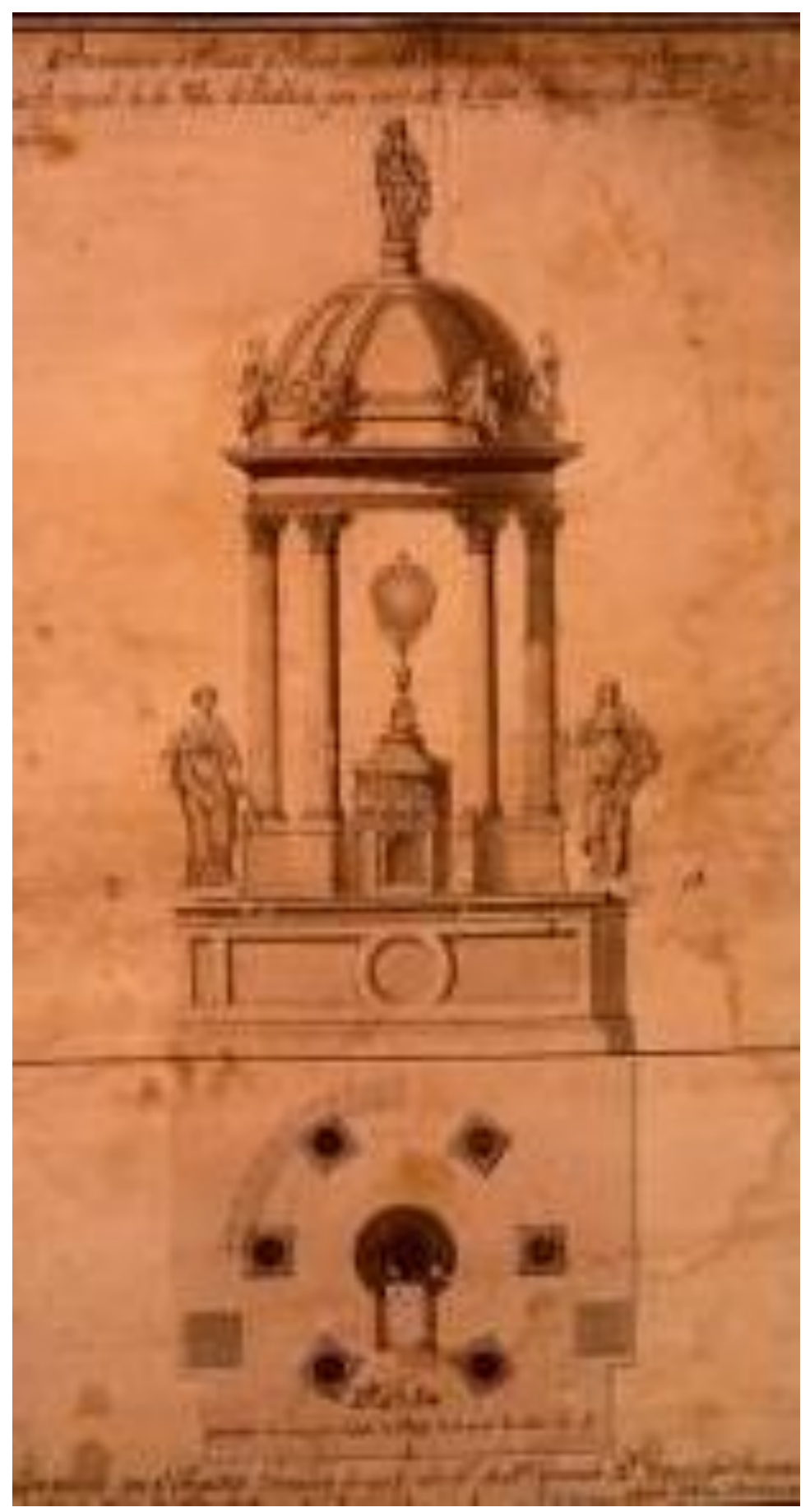

Imagen 6. Proyecto de tabernáculo para la capilla mayor, de 1816 


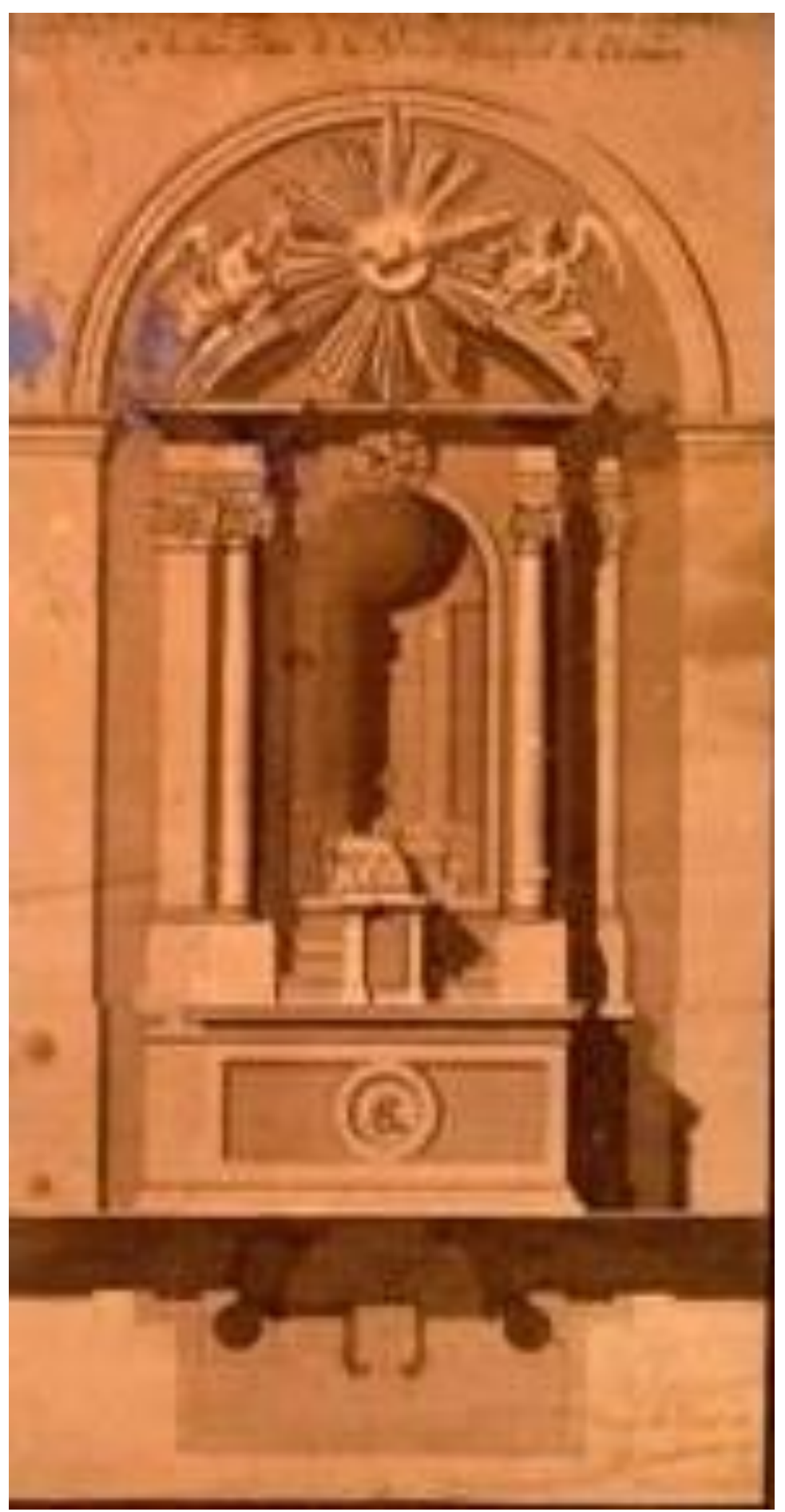

Imagen 7. Proyecto de retablo para las capillas, de 1816 


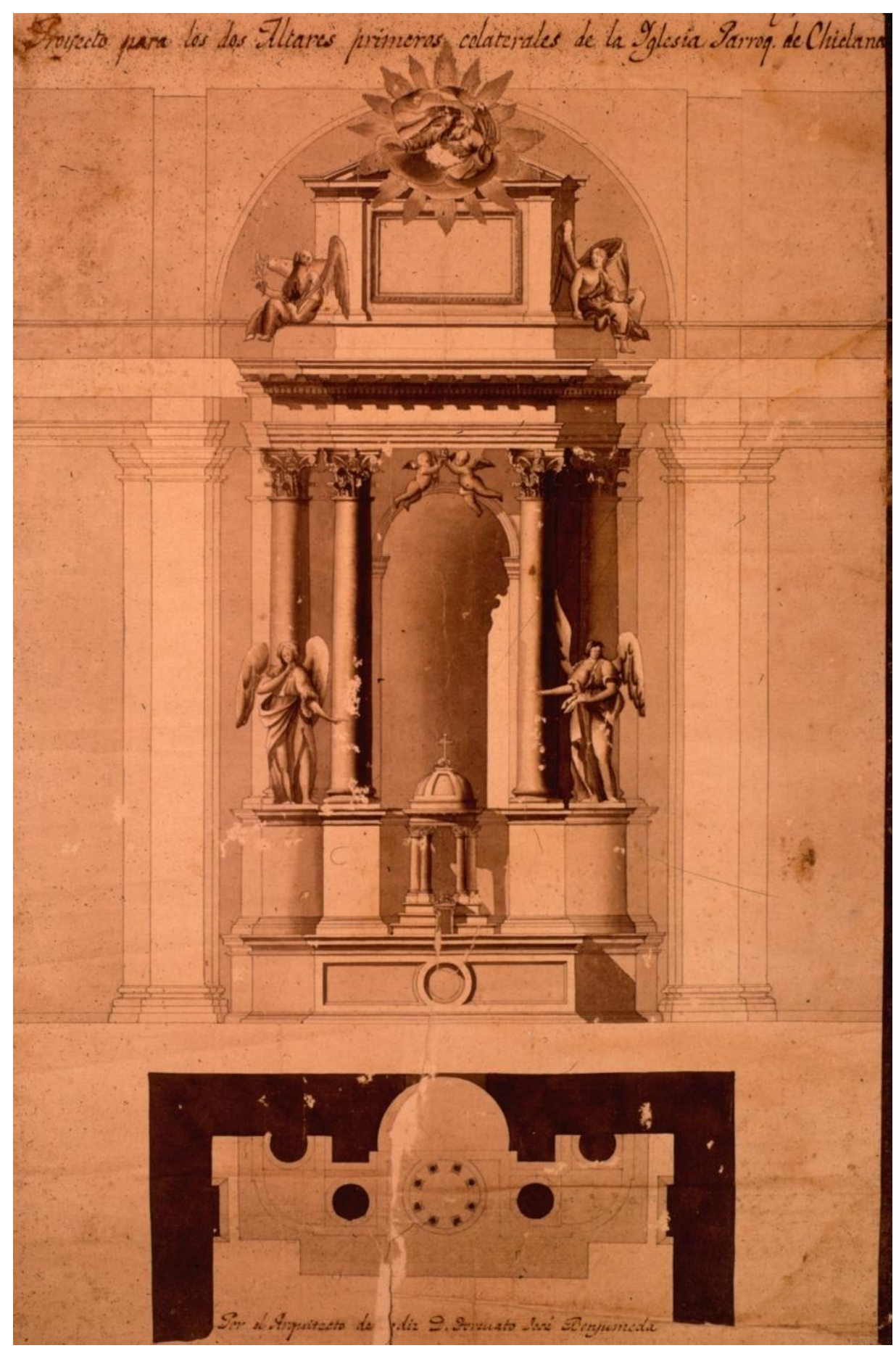

Imagen 8. Proyecto de retablo para el teórico crucero, de 1816 